\title{
Regulation of Arginine and Pyrimidine Biosynthesis in Pseudomonas putida
}

\author{
By S. CONDON AND J. K. COLLINS \\ Department of Dairy and Food Microbiology, University College, Cork, Ireland \\ AND G. A. O'DONOVAN \\ Department of Biochemistry and Biophysics, Texas $A$ and $M$ University, \\ College Station, Texas 77843 , U.S.A.
}

(Received 2 April 1975; revised II September 1975)

\begin{abstract}
SUMMARY
Repression of biosynthetic enzyme synthesis in Pseudomonas putida is incomplete even when the bacteria are growing in a nutritionally complex environment. The synthesis of four of the enzymes of the arginine biosynthetic pathway ( $N$-acetyl- $\alpha$-glutamokinase $/ N$-acetylglutamate- $\gamma$-semialdehyde dehydrogenase, ornithine carbamoyltransferase and acetylornithine- $\delta$-transaminase) could be repressed and derepressed, but the maximum difference observed between repressed and derepressed levels for any enzyme of the pathway was only 5 -fold (for ornithine carbamoyltransferase). No repression of five enzymes of the pyrimidine biosynthetic pathway (aspartate carbamoyltransferase, dihydro-orotase, dihydroorotate dehydrogenase, orotidine- 5 - -phosphate pyrophosphorylase and orotidine5 -phosphate decarboxylase) could be detected on addition of pyrimidines to minimal asparagine cultures of $P$. putida A90, but a $1 \cdot 5$ - to 2 -fold degree of derepression was found following pyrimidine starvation of pyrimidine auxotrophic mutants of $P$. putida A90. Aspartate carbamoyltransferase in crude extracts of $P$. putida A90 was inhibited in vitro by (in order of efficiency) pyrophosphate, CTP, UTP and ATP, at limiting but not at saturating concentrations of carbamoyl phosphate.
\end{abstract}

\section{INTRODUCTION}

Regulation of the synthesis of biosynthetic monomers such as amino acids, purines and pyrimidines in the enteric bacteria is clearly understood in terms of allosteric inhibition of key enzymes and repression of synthesis of biosynthetic enzymes. The control is so effective that little or no wasteful formation of either the small molecules or the macromolecules needed for their biosynthesis occurs, irrespective of the nutritional composition of the bacterial environment. Although information is still limited, it appears that the pseudomonads may not be so efficient in regulating enzyme biosynthesis, especially under conditions of an abundance of biosynthetic monomers in their external environment.

The synthesis of biosynthetic monomers in pseudomonads appears to be efficiently regulated through feed-back inhibition of strategically-placed allosteric proteins. Addition of a mixture of the 20 amino acids contained in proteins to the culture medium caused a $75 \%$ reduction in endogenous synthesis of amino acids in Pseudomonas putida (Collins, I 974). Several workers (Udaka, 1966; Jensen, Nasser \& Nester, 1967; Cohen, Stanier \& Le Bras, I969; Robert-Gero, Poiret \& Cohen, 1970; Chou \& Gunsalus, I971; Isaac \& Holloway, 1972; Haas, Kurer \& Leisinger, 1972) have demonstrated the existence of allosteric enzymes, regulated by end-product inhibition, in key positions in amino acid biosynthetic pathways in pseudomonads. Likewise pyrimidine biosynthesis is probably 
regulated through allosteric inhibition of aspartate carbamoyltransferase (Neumann \& Jones, I964; Isaac \& Holloway, 1968).

However, evidence for efficient regulation of the biosynthesis of anabolic enzymes in pseudomonads is not convincing. There is no report of significant repression or derepression of a complete biosynthetic pathway. Constitutive synthesis of enzymes and minor variations between repressed and derepressed enzyme levels appear to be the rule rather than the exception (Udaka, I966; Ramos et al., I967; Waltho, I968; Isaac \& Holloway, 1968, 1972; Robert-Gero et al., I970; Chou \& Gunsalus, I97I; Maurer \& Crawford, 197I; Voellmy \& Leisinger, 1972).

Unlike enteric bacteria, strains of $P$. putida do not respond to complex supplementation of a minimal medium (containing a readily metabolizable carbon source) by growing appreciably faster (Collins \& Condon, 1972). In a search for biosynthetic systems which do not respond to an abundance of biosynthetic monomers in the external environment, the regulation of both the arginine and pyrimidine pathways was examined in this bacterium.

\section{METHODS}

Bacterial strains. Strains A90 and A775 of Pseudomonas putida were originally obtained from the Department of Bacteriology and Immunology, University of California, Berkeley, California, U.S.A., and were classified by Stanier, Palleroni \& Doudoroff (1966).

Growth media and growth measurements. The basal medium used contained, per litre: $\mathrm{KH}_{2} \mathrm{PO}_{4}, 6.8 \mathrm{~g} ; \mathrm{Na}_{2} \mathrm{HPO}_{4}, 7 \cdot \mathrm{I} \mathrm{g} ;\left(\mathrm{NH}_{4}\right)_{2} \mathrm{SO}_{4}, \mathrm{I} \cdot 0 \mathrm{~g} ; \mathrm{MgSO}_{4}, 0.6 \mathrm{~g} ; \mathrm{CaCl}_{2} .2 \mathrm{H}_{2} \mathrm{O}, 79 \mathrm{mg}$; $\mathrm{FeSO}_{4} \cdot 7 \mathrm{H}_{2} \mathrm{O}, 2 \mathrm{mg}$; $\left(\mathrm{NH}_{4}\right)_{6} \mathrm{Mo}_{7} \mathrm{O}_{24} \cdot{ }_{4} \mathrm{H}_{2} \mathrm{O}, 0.2 \mathrm{mg}$; nitrilotriacetic acid, $0.2 \mathrm{~g}$; Hutner's metals ' 44 ' (Cohen-Bazire, Sistrom \& Stanier, 1957), I ml. The carbon source, asparagine, and supplementary amino acids and pyrimidines were added after separate sterilization. For growth experiments, liquid cultures ( $100 \mathrm{ml}$ or less) were grown in $250 \mathrm{ml}$ Erlenmeyer flasks, and aerated by shaking in a Gallenkamp metabolic shaking incubator. The growth temperature was maintained at $30 \pm 0 \cdot 2{ }^{\circ} \mathrm{C}$. Growth was monitored by measurements of $E_{660}$ using a Pye Unicam SP500 spectrophotometer.

Shift-down experiments were performed with cultures growing exponentially in Difco Casamino acid-supplemented minimal asparagine medium. When exponential growth was established, the bacteria were centrifuged, washed and divided into two portions. One portion was suspended in minimal asparagine medium while the other was resuspended in the original Casamino acid-supplemented minimal asparagine medium as a control.

Preparation of cell-free extracts. Extracts were prepared from sonically-disrupted exponentially growing bacteria in either $0^{\circ} \mathrm{I}$ M-sodium-potassium phosphate buffer, $\mathrm{pH} 7 \cdot 0$ (for arginine enzyme assays) or $0.02 \mathrm{M}$-tris- $\mathrm{HCl}$ buffer, $\mathrm{pH} 8.0$ (for pyrimidine pathway enzymes) containing I mM-2-mercaptoethanol. Extracts were dialysed for $\mathrm{I} 2$ to $\mathrm{I} 8 \mathrm{~h}$ against the same buffer at $2{ }^{\circ} \mathrm{C}$. The protein concentration of the extracts was determined according to Lowry et al. (195I).

Enzyme assays. With the exception of $N$-acetyl- $\alpha$-glutamokinase and $N$-acetylglutamate$\gamma$-semialdehyde dehydrogenase which were assayed at $20^{\circ} \mathrm{C}$, the enzymes were assayed at $30{ }^{\circ} \mathrm{C}$. A unit of enzyme activity is expressed in $\mu \mathrm{mol}$ of substrate reacting $/ \mathrm{min}$.

$N$-acetyl- $\alpha$-glutamokinase, EC. $2 \cdot 7 \cdot 2.8$ and $N$-acetylglutamate- $\gamma$-semialdehyde dehydrogenase, EC. I.2.I.38. These two enzyme activities were assayed simultaneously according to the procedure of Baich \& Vogel (I962).

Acetylornithine- $\delta$-transaminase, EC. 2.6.I.II. The procedure of Albrecht \& Vogel (1964) was used. 
Ornithine carbamoyltransferase, EC. 2.1.3.3. This biosynthetic enzyme was assayed by a modification (Sellers, 1974) of the original (Archibald, 1944) method. In this modification citrulline was measured by the colorimetric method of Prescott \& Jones (1969) for the assay of carbamoyl aspartate and other ureido compounds. The assay mixture contained, per $\mathrm{ml}: \mathrm{I} 00 \mu \mathrm{mol}$ tris- $\mathrm{HCl}$ buffer, $\mathrm{pH} 8.5 ; 5 \mu \mathrm{mol}$ L-ornithine, $\mathrm{pH} 8.5 ; 400 \mu \mathrm{g}$ carbamoyl phosphate (dilithium salt); and cell-free extract. At pH 8.5 an inducible catabolic ornithine carbamoyltransferase also present in this strain is inactive (Stalon et al. 1967).

Aspartate carbamoyltransferase, EC. 2.1.3.2. This enzyme was assayed according to the optimal conditions described by Neumann \& Jones (1964) for Pseudomonas fluorescens. The carbamoyl aspartate produced was determined colorimetrically (Prescott \& Jones, 1969). In the experiment on allosteric inhibition of aspartate carbamoyltransferase, the substrates carbamoyl phosphate and L-aspartate were varied as described in the text.

Dihydro-orotate dehydrogenase, EC. 1.3.3.1. The method of O'Donovan \& Gerhart (1972) was used.

Dihydro-orotase, EC. 3.5.2.3. This was assayed by the method of Beckwith et al. (I962). The carbamoyl aspartate formed from dihydro-orotate was determined colorimetrically (Prescott \& Jones, I969).

Orotidine-5'-phosphate pyrophosphorylase, EC. 2.4.2.10. The method of Beckwith et al. (1962) as modified by Wild (1971) was used. The assay mixture contained, per ml: $0.6 \mu \mathrm{mol} 5$-phospho- $\alpha$-D-ribose I-diphosphate; and cell-free extract. After 5 min pre-incubation at $30{ }^{\circ} \mathrm{C}$, the reaction was started by the addition of L-orotate $(10 \mu \mathrm{mol})$, and followed by observing the decrease in $E_{295}$.

Orotidine-5'-phosphate decarboxylase, EC. 4.I.I.23. A modification of the method of Beckwith et al. ( I 962) was used. The assay mixture contained, per $\mathrm{ml}$ : $10 \mu \mathrm{mol}$ tris- $\mathrm{HCl}$ buffer, $\mathrm{pH} 8.7 ; 2 \mu \mathrm{mol} \mathrm{MgCl}_{2}$; and cell-free extract. After $10 \mathrm{~min}$ pre-incubation at $30^{\circ} \mathrm{C}$, the reaction was started by the addition of orotidine $5^{\prime}$-phosphate $(0.2 \mu \mathrm{mol})$, and its disappearance was followed spectrophotometrically at $285 \mathrm{~nm}$.

Isolation of mutants. Auxotrophic mutants which required either a pyrimidine or a pyrimidine plus arginine for growth were isolated by penicillin counterselection of $\mathrm{N}$ methyl- $N^{\prime}$-nitro- $N$-nitrosoguanidine-treated cultures of $P$. putida A90. The mutants were characterized by assaying for pyrimidine and arginine path way enzymes. Three of these mutants were used in the present study: $P$. putida A90 pyr $A$, defective in the carbamoyl phosphate synthetase reaction; $P$. putida A90 pyr $B$, defective in the aspartate carbamoyltransferase reaction; $P$. putida A90 pyrF, defective in the orotidine-5'-phosphate decarboxylase reaction.

\section{RESULTS}

\section{Withdrawal of an amino acid supplement from $P$. putida cultures}

When either of the two $P$. putida strains growing exponentially for many generations in a medium containing asparagine (as the primary carbon source) plus Casamino acids was harvested, washed and transferred to a minimal asparagine medium, complete cessation of growth did not occur (Fig. 1). Growth continued at a reduced rate until the full minimal asparagine rate was achieved after 70 to $90 \mathrm{~min}$. Thus, even in the presence of a full complement of amino acids, a repression of the synthesis of any of the amino acid biosynthetic enzymes sufficient to prevent growth is not a characteristic of this bacterium. 


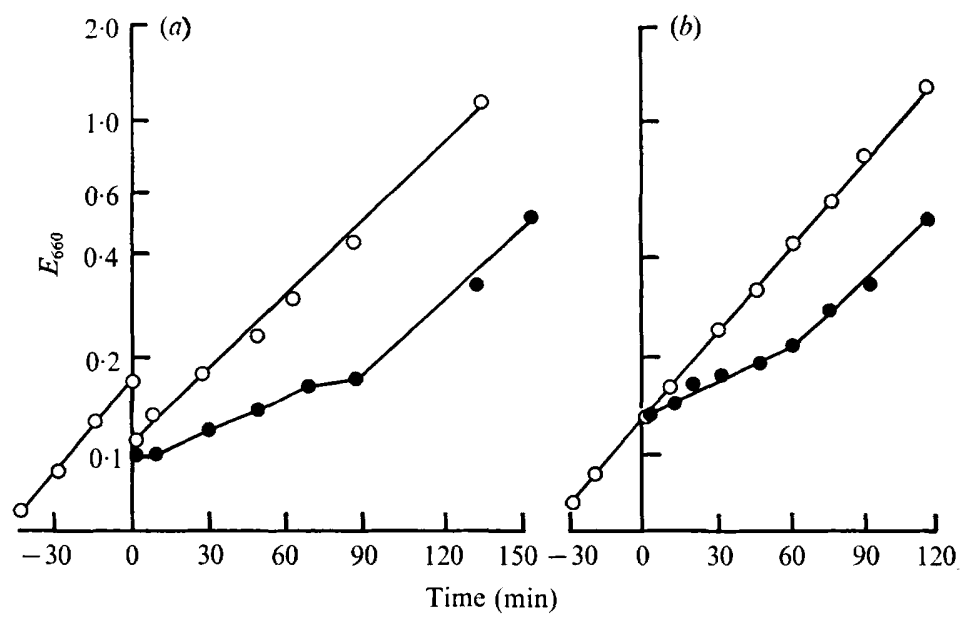

Fig. I. Shift-down of $P$. putida strains A90 $(a)$ and A775 $(b)$ from Casamino acid-supplemented asparagine minimal medium $(O)$ to minimal asparagine medium (O) at $30^{\circ} \mathrm{C}$. Exponentiallygrowing cells from the Casamino acid media were harvested at zero time by centrifugation, washed and resuspended in the minimal asparagine medium. Growth was followed as $E_{660}$.

Table I. Derepression of arginine biosynthetic enzymes in P. putida A90 pyrA growing in minimal asparagine medium containing uracil $(20 \mu \mathrm{g} / \mathrm{ml})$ and arginine $(100 \mu \mathrm{g} / \mathrm{ml})$ on deprivation of arginine

\begin{tabular}{ccccc} 
& \multicolumn{4}{c}{ Specific activity* } \\
Duration of starvation $(h)$ & $\ldots$ & \multicolumn{1}{c}{0} & \multicolumn{1}{c}{ I } & 2 \\
mialdehyde dehydrogenase $\dagger$ & & I00 & 186 & 126 \\
& & 100 & 83 & 63 \\
& & 100 & 528 & 468
\end{tabular}

$\begin{array}{lrrr}N \text {-acetyl- } \alpha \text {-glutamokinase }+N \text {-acetylglutamate- } \gamma \text {-semialdehyde dehydrogenase } \dagger & \text { 100 } & 186 & 126 \\ \text { Acetylornithine- } \delta \text {-transaminase } & 100 & 83 & 63 \\ \text { Ornithine carbamoyltransferase } & 100 & 528 & 468\end{array}$

* The specific activity of arginine enzymes, expressed as a percentage of the value obtained for cells grown in the presence of arginine. The specific activities (units/mg protein) corresponding to $100 \%$ activity for $N$-acetyl- $\alpha$-glutamokinase $+N$-acetylglutamate $-\gamma$-semialdehyde dehydrogenase, acetylorinthine- $\delta$-transaminase, and ornithine carbamoyltransferase were $1.83,0.83$ and 0.13 , respectively.

$\dagger$ Assayed simultaneously.

\section{Regulation of synthesis of arginine biosynthetic enzymes in P. putida A90}

Enzymes of the arginine biosynthetic pathway were assayed in cell-free extracts of $P$. putida A90 grown from inoculation in minimal asparagine media both in the presence and absence of arginine (I00 $\mu \mathrm{g} / \mathrm{ml}$ ). The level of ornithine carbamoyltransferase in the presence of arginine was $39 \%$ of that in its absence, indicating a $2 \cdot 5$-fold repression of synthesis by arginine. $N$-acetyl- $\alpha$-glutamokinase and $N$-acetylglutamate- $\gamma$-semialdehyde dehydrogenase (assayed together) were repressed by only 30\%. The specific activity of acetylornithine$\delta$-transaminase was not reduced by growth in the presence of arginine - in fact it increased by $25 \%$. These results were confirmed in a derepression experiment with the auxotrophic mutant $P$. putida A90 pyr $A$. Bacteria were grown for many generations in a minimal asparagine medium containing $100 \mu \mathrm{g}$ arginine plus $20 \mu \mathrm{g}$ uracil $/ \mathrm{ml}$, harvested, and resuspended in a similar medium but without the arginine. Extracts made $\mathrm{I}$ and $2 \mathrm{~h}$ after removal of the arginine were assayed for arginine biosynthetic enzymes and compared with an extract of similar bacteria grown in the presence of arginine (Table I). Fivefold derepression of ornithine carbamoyltransferase and approximately 2 -fold derepression of $N$-acetyl- $\alpha$ - 
Table 2. Derepression of pyrimidine biosynthetic enzymes in P. putida A9o pyrF growing in minimal asparagine medium containing uracil $(20 \mu \mathrm{g} / \mathrm{ml})$ on deprivation of uracil

\begin{tabular}{|c|c|c|c|c|}
\hline \multirow[b]{2}{*}{ Duration of starvation $(h)$. } & \multicolumn{4}{|c|}{ Specific activity* } \\
\hline & 0 & 0.5 & $1 \cdot 0$ & $\mathrm{I} \cdot 5$ \\
\hline Aspartate carbamoyltransferase & 100 & 129 & 140 & 162 \\
\hline Dihydro-orotase & 100 & I 15 & 120 & 17 \\
\hline Dihydro-orotate dehydrogenase & 100 & 77 & I 20 & 17 \\
\hline Orotidine- 5 '-phosphate pyrophosphorylase & 100 & I 34 & I 33 & 172 \\
\hline Orotidine- $5^{\prime}$-phosphate decarboxylase & 0 & $\begin{array}{r}0 \\
0\end{array}$ & 0 & \\
\hline
\end{tabular}

* The specific activity of pyrimidine pathway enzymes following uracil starvation, expressed as a percentage of the value obtained for cells grown in the presence of uracil. The specific activities (units/mg protein) corresponding to $100 \%$ activity for aspartate carbamoyltransferase, dihydro-orotase, dihydroorotate dehydrogenase and orotidine-5'-phosphate pyrophosphorylase were $0.34,0.25,0.0026$ and 0.017 , respectively.

glutamokinase and/or $N$-acetylglutamate- $\gamma$-semialdehyde dehydrogenase occurred after $\mathrm{I} \mathrm{h}$, while the specific activity of acetylornithine- $\delta$-transaminase dropped by approximately I $\%$ during the same period. The levels of all arginine pathway enzymes assayed decreased during the second hour of arginine starvation.

\section{Regulation of synthesis of pyrimidine pathway enzymes in P. putida $\mathrm{A} 90$}

The presence of uracil in the growth medium did not repress synthesis of any pyrimidine pathway enzyme measured. The levels of five enzymes of the pyrimidine biosynthetic pathway (aspartate carbamoyltransferase, dihydro-orotase, dihydro-orotate dehydrogenase, orotidine-5'-phosphate pyrophosphorylase and orotidine-5'-phosphate decarboxylase) in extracts of $P$. putida A90 grown in minimal asparagine medium with $20 \mu \mathrm{g}$ uracil $/ \mathrm{ml}$, were similar to those in minimal asparagine medium without uracil. As uracil fully satisfied the pyrimidine requirements of pyrimidine auxotrophic mutants, it is unlikely that the lack of repression was due to transport difficulties or to failure to convert uracil to the various phosphorylated pyrimidine derivatives required for growth. It is also unlikely that the lack of repression was due to catabolism of uracil, since $P$. putida cannot use uracil as carbon or nitrogen source. The level of pyrimidine pathway enzymes in P. putida A90 is regulated, however, as starvation of pyrimidine auxotrophs does result in a modest increase in the specific activity of all the enzymes of the pathway. When $P$. putida A9o pyrF, growing exponentially in asparagine minimal medium containing $20 \mu \mathrm{g}$ uracil $/ \mathrm{ml}$, was transferred to a similar medium but without uracil, the concentration of pyrimidine pathway enzymes gradually increased by about 62 to $75 \%$ over a 90 min period (Table 2 ). A similar result was obtained with another mutant, $P$. putida A9o pyrB, which was switched from uracil to cytosine as a pyrimidine source. Cytosine fulfilled the pyrimidine requirement for auxotrophic mutants of $P$. putida only with difficulty, as the growth rate was reduced $7-$ to 8 -fold compared with uracil supplementation. Growth of a pyrimidine auxotrophic mutant of $P$. putida A9o with cytosine, therefore, is growth under conditions of pyrimidine limitation.

When $P$. putida A90 pyr $B$ growing exponentially in minimal asparagine medium containing $50 \mu \mathrm{g}$ each of both uracil and cytosine $/ \mathrm{ml}$ was harvested and resuspended in the same medium containing cytosine alone, the concentration of pyrimidine pathway enzymes increased approximately 2 -fold after $3 \mathrm{~h}$. 
Table 3. Allosteric inhibition of aspartate carbamoyltransferase in extracts of P. putida A90

\begin{tabular}{|c|c|c|c|}
\hline \multirow[b]{2}{*}{ Inhibitor } & \multirow{2}{*}{$\begin{array}{l}\text { Inhibitor } \\
\text { concn } \\
(\mathrm{mM})\end{array}$} & \multicolumn{2}{|c|}{ Activity* $(\%)$} \\
\hline & & $\begin{array}{l}\text { L-Aspartate } \uparrow \\
\text { limiting }\end{array}$ & $\begin{array}{c}\text { Carbamoyl phosphate } \\
\text { limiting }\end{array}$ \\
\hline None & & 100 & 100 \\
\hline Pyrophosphate & $\begin{array}{l}0.05 \\
0.5 \\
5 \cdot 0\end{array}$ & $\begin{array}{l}94 \\
85 \\
47\end{array}$ & $\begin{array}{r}104 \\
24 \\
7\end{array}$ \\
\hline СТP & $\begin{array}{l}0.05 \\
0.5 \\
5.0\end{array}$ & $\begin{array}{r}100 \\
95 \\
83\end{array}$ & $\begin{array}{r}116 \\
96 \\
16\end{array}$ \\
\hline UTP & $\begin{array}{l}0.05 \\
0.5 \\
5.0\end{array}$ & $\begin{array}{l}9 I \\
93 \\
9 I\end{array}$ & $\begin{array}{l}80 \\
76 \\
50\end{array}$ \\
\hline ATP & $\begin{array}{l}0.05 \\
0.5 \\
5.0\end{array}$ & $\begin{array}{r}100 \\
87 \\
81\end{array}$ & $\begin{array}{r}111 \\
105 \\
68\end{array}$ \\
\hline UMP & $\begin{array}{l}0.05 \\
0.5 \\
5.0\end{array}$ & $\begin{array}{r}103 \\
97 \\
91\end{array}$ & $\begin{array}{l}\text { I I } 6 \\
\text { I I } 5 \\
\text { I } 25\end{array}$ \\
\hline
\end{tabular}

* The specific activity corresponding to $100 \%$ activity was 0.31 units/mg protein.

† L-Aspartate, I mm; carbamoyl phosphate, I0 mм.

L-Aspartate, ro mm; carbamoyl phosphate, $0.5 \mathrm{~mm}$.

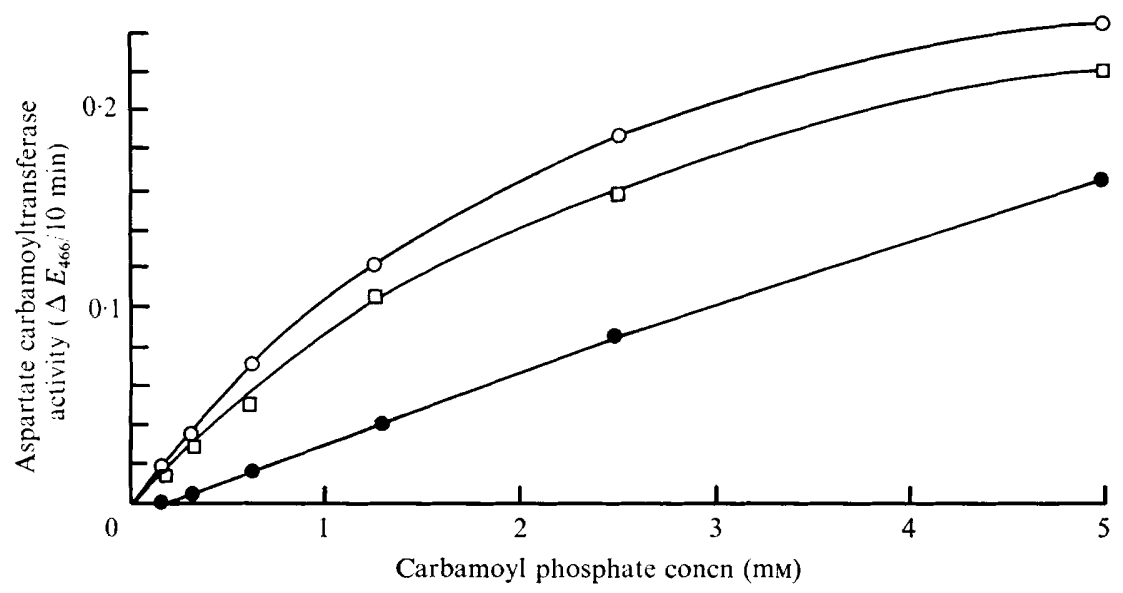

Fig. 2. Allosteric inhibition of aspartate carbamoyltransferase activity (extinction at $466 \mathrm{~nm} / 10 \mathrm{~min}$ ) in dialysed extracts of $P$. putida A90. The enzyme was assayed alone $(O)$ and in the presence of $5 \mathrm{~mm}-\mathrm{CTP}(\bigcirc)$ or $5 \mathrm{~mm}$-UTP $(\square)$. The concentration of L-aspartate was saturating at $10 \mathrm{~mm}$ while the concentration of carbamoyl phosphate was varied as indicated.

\section{Allosteric inhibition of aspartate carbamoyltransferase}

The pyrimidine pathway in $P$. putida A90 might be regulated in vivo through allosteric inhibition of aspartate carbamoyltransferase under conditions of carbamoyl phosphate limitation. With carbamoyl phosphate saturation (and even with L-aspartate limitation) only sodium pyrophosphate of the possible effectors tested had any great inhibitory effect 
on the in vitro assay of aspartate carbamoyltransferase in dialysed extracts of $P$. putida A90. With carbamoyl phosphate limitation, however, several pyrophosphorylated compounds tested inhibited the activity to varying degrees depending on their concentration (Table 3). The greatest degree of inhibition was noted with sodium pyrophosphate. Of the three nucleoside triphosphates, CTP, UTP and ATP, CTP proved the most effective inhibitor. UMP, the only non-pyrophosphorylated derivative tested, proved slightly stimulatory. The superiority of CTP over UTP at $5 \mathrm{~mm}$ can be seen from Fig. 2, in which is shown activity-substrate concentration plots of aspartate carbamoyltransferase (in dialysed extracts of $P$. putida A90) alone and in the presence of either CTP or UTP. In this experiment L-aspartate was kept at saturation levels while the carbamoyl phosphate concentration was varied. At $5 \mathrm{~mm}$, CTP was a much more effective allosteric inhibitor than UTP. At low carbamoyl phosphate concentrations, CTP caused go to $100 \%$ inhibition whereas UTP only barely ( 5 to $10 \%$ ) inhibited the enzyme.

\section{DISCUSSION}

This study shows that end-product repression of synthesis of the pathway enzymes makes a contribution to the regulation of the arginine biosynthetic pathway in $P$. putida A90. The repressive effect is not spectacular. The greatest difference between repressed and derepressed levels was only 5 -fold (for ornithine carbamoyltransferase), in marked contrast to the 80-fold repression of the same enzyme in Escherichia coli KI 2 (Maas, 1965). This result agrees with those of other investigators of the regulation of arginine biosynthesis in pseudomonads. Repression of synthesis of ornithine carbamoyltransferase by arginine has been reported by several groups (Udaka, 1966; Ramos et al., 1967; Chou \& Gunsalus, 1971; Voellmy \& Leisinger, 1972; Isaac \& Holloway, 1972); the extent was about 2- to 6-fold, except for experiments in which arginine was the sole carbon source, where 50- to 100 -fold repression was observed (Voellmy \& Leisinger, 1972; Isaac \& Holloway, 1972).

Information on the regulation of synthesis of the other enzymes of the arginine biosynthetic pathway in pseudomonads is meagre. In $P$. aeruginosa, synthesis of only one ( $N$-acetylglutamate- $\gamma$-semialdehyde dehydrogenase) of the seven other enzymes was repressed by arginine (Voellmy \& Leisinger, 1972; Isaac \& Holloway, 1972) and the repression reported was only 2 -fold. Chou \& Gunsalus ( 1971) observed that the synthesis of $N$-acetyl$\alpha$-glutamokinase in $P$. putida PpGi was repressed by acetylglutamate and acetylornithine, while synthesis of ornithine acetyltransferase (and ornithine carbamoyltransferase) was repressed by arginine. Our work indicates that the synthesis of at least one of the two enzymes $N$-acetyl- $\alpha$-glutamokinase and $N$-acetylglutamate- $\gamma$-semialdehyde dehydrogenase (which were assayed together) is slightly repressed by arginine and derepressed by arginine limitation in P. putida A90. Chou \& Gunsalus (1971) and Voellmy \& Leisinger (1972) reported that acetylornithine- $\delta$-transaminase was inducible by arginine in $P$. putida PpG I and $P$. aeruginosa respectively, a result which we confirm here for $P$. putida A90.

Similar observations have been made with other biosynthetic pathways in pseudomonads. Waltho (I968) could find no evidence of repression control of the phenylalanine pathway in P. aeruginosa. Robert-Gero et al. (1970) working on repression of aspartokinase synthesis and Maurer \& Crawford (1971) on the regulation of the tryptophan pathway in strains of $P$. putida found that the presence of the amino acid in the bacterial environment caused only minor repression of enzymes of the specific biosynthetic pathway. Maurer \& Crawford (1971) did, however, isolate analogue-resistant mutants which had 15- to 20-fold derepressed levels of three of the tryptophan biosynthetic enzymes. The mutations mapped 
outside the tryptophan structural genes, suggesting a similarity with the $\operatorname{trp} R$ mutations in E. coli. It is possible, therefore, that in pseudomonads the wild-type aporepressor element of the tryptophan biosynthetic pathway does not respond dramatically to changes in the concentration of tryptophan but that a much larger response can be produced by genetic changes in the aporepressor.

The synthesis of the pyrimidine pathway enzymes in $P$. putida A90 was not significantly altered by the presence of exogenous uracil, but the specific activity of the enzymes increased I.5- to 2-fold on pyrimidine starvation of auxotrophic mutants, indicating some regulation over synthesis of pyrimidine biosynthetic enzymes. This result differs from that of Isaac \& Holloway (1968), who failed to detect repression or derepression of pyrimidine enzyme synthesis in $P$. aeruginosa.

Our observations on inhibition of aspartate carbamoyltransferase suggest that, as in other bacteria, it probably plays an important role in the regulation of pyrimidine biosynthesis. The enzyme appears to resemble that in $P$. fluorescens (Neumann \& Jones, I964; Adair \& Jones, I 972) more closely than that in $P$. aeruginosa (Isaac \& Holloway, 1968). In both $P$. fluorescens and $P$. putida pyrophosphate and the nucleotides CTP, UTP and ATP were inhibitory at limiting carbamoyl phosphate concentrations and pyrophosphate was the most effective inhibitor. Aspartate carbamoyltransferase in dialysed extracts of $P$. putida A90 differs, however, from that of $P$. fuorescens in that little allosteric inhibition was detected under conditions of carbamoyl phosphate saturation and also in that CTP was the most powerful trinucleotide effector tested.

We are grateful for the technical assistance of Miss Kayron Dube. The work was supported in part by the Robert A. Welch Foundation, Houston, Texas, U.S.A.

\section{REFERENCES}

ADAIR, L. B. \& JONES, M. E. (I972). Purification and characteristics of aspartate transcarbamylase from Pseudomonas fluorescens. Journal of Biological Chemistry 247, 2308-23 I 5.

Albrecht, A. M. \& VoGel, H. J. (1964). Acetylornithine- $\delta$-transaminase; partial purification and repression behaviour. Journal of Biological Chemistry 198, 165-185.

ARCHIBALD, R. M. (1944). Determination of citrulline and allantoin and demonstration of citrulline in blood plasma. Journal of Biological Chemistry $\mathbf{5 6}$, I 2 I-I 42.

BAICH, A. \& VoGEL, H. J. (I962). $N$-acetyl- $\alpha$-glutamokinase and $N$-acetylglutamate- $\gamma$-semialdehyde dehydrogenase: repressible enzymes of arginine synthesis in Escherichia coli. Biochemical and Biophysical Research Communications 7, 49I-496.

Beckwith, J. R., Pardee, A. B., Austrian, R. \& Jacob, J. (I962). Co-ordination of the synthesis of the enzymes in the pyrimidine pathway of E. coli. Journal of Molecular Biology 5, 6r 8-634.

Chou, I. N. \& Gunsalus, I. C. (1971). Arginine biosynthesis in Pseudomonas putida. Bacteriological Proceedings, p. 231.

Cohen, G. N., Stanier, R. Y. \& Le Bras, G. (I969). Regulation of the biosynthesis of amino acids of the aspartate family in coliform bacteria and pseudomonads. Journal of Bacteriology 99, 79I-80I.

Cohen-Bazire, G., Sistrom, W. R. \& Stanier, R. Y. (I957). Kinetic studies of pigment synthesis by nonsulfur purple bacteria. Journal of Cellular and Comparative Physiology 49, 25-68.

Collins, J. K. (1974). Regulation of growth and biosynthesis in Pseudomonas putida. Ph.D. thesis, University College, Cork.

Collins, J. K. \& Condon, S. (1972). Effect of amino acid supplementation on growth of Pseudomonas putida A.3.I 2. Biochemical Society Transactions $\mathbf{r}, 303$.

HaAs, D., Kurer, V. \& LeISINGer, T. (1972). N-acetylglutamate synthetase of Pseudomonas aeruginosa. An assay in vitro and feed-back inhibition by arginine. European Journal of Biochemistry 3r, 290-295.

IsAaC, J. H. \& HollowaY, B. W. (I968). Control of pyrimidine biosynthesis in Pseudomonas aeruginosa. Journal of Bacteriology $96,1732-174 \mathrm{I}$.

IsaAC, J. H. \& Holloway, B. W. (1972). Control of arginine biosynthesis in Pseudomonas aeruginosa. Journal of General Microbiology 73, 427-438.

Jensen, R. A., Nasser, D. S. \& Nester, E. W. (1967). Comparative control of a branch-point enzyme in micro-organisms. Journal of Bacteriology 94, $1582-1593$. 
Lowry, O. H., Rosebrough, N. J., Farr, A. L. \& Randall, R. J. (I95I). Protein measurement with the Folin phenol reagent. Journal of Biological Chemistry 193, 265-275.

MaAs, W. K. (1965). Genetic defects affecting an arginine permease and repression of arginine synthesis in Escherichia coli. Federation Proceedings 211 , $1239-1242$.

MaUrer, R. \& CRAWFord, I. P. (I97I). New regulator mutation affecting some of the tryptophan genes in Pseudomonas putida. Journal of Bacteriology 106, 33 I-338.

Neumann, J. \& Jones, M. E. (1964). End-product inhibition of aspartate transcarbamylase in various species. Archives of Biochemistry and Biophysics 104, 438-447.

O'Donovan, G. A. \& Gerhart, J. C. ( I 972). Isolation and partial characterisation of regulatory mutants of the pyrimidine pathway in Salmonella typhimurium. Journal of Bacteriology ro9, 1085-1096.

Prescott, L. M. \& Jones, M. E. (1969). Modified methods for the determination of carbamyl aspartate. Analytical Biochemistry 32, 408-419.

Ramos, F., Stalon, V., PJerard, A. \& Wiame, J. M. (1967). The specialisation of the two ornithine carbamoyl transferases of Pseudomonas. Biochimica et biophysica acta 139, 98-106.

Robert-Gero, M., Poiret, M. \& Cohen, G. N. (1970). The aspartate kinase of Pseudomonas putida. Regulation of synthesis and activity. Biochimica et biophysica acta 206, 17-30.

SELlERS, K. (1974). The partial characterization of the ornithine transcarbamylase enzymes from the two genera of bacteria, Escherichia coli and Aeromonas proteolytica. Ph.D. thesis, Texas A and M University, College Station, Texas, U.S.A.

Stalon, V., Ramos, F., Pierard, A. \& Wiame, J. M. (1967). The occurrence of a catabolic and an anabolic ornithine carbamoyl transferase in Pseudomonas. Biochimica et biophysica acta I39, 9I-97.

Stanier, R. Y., Palleroni, N. J. \& Doudoroff, M. (I966). The aerobic pseudomonads: a taxonomic study. Journal of General Microbiology 43, I 59-27I.

Udaka, S. (I966). Pathway specific pattern of control of arginine biosynthesis in bacteria. Journal of Bacteriology 91, 617-62 I.

Voellmy, R. \& Leisinger, T. (1972). Regulation of enzyme synthesis in the arginine system of Pseudomonas aeruginosa. Journal of General Microbiology 73, xiii.

Waltho, J. A. (1968). Regulation of phenylalanine biosynthesis in Pseudomonas aeruginosa. Ph.D. thesis, University of Melbourne, Australia.

Wild, J. (1971). Studies in the regulation of pyrimidine biosynthesis in Serratia marcescens. Ph.D. thesis, University of California, Riverside, U.S.A. 